\title{
STRATEGI PENGELOLAAN MAHAKA SQUARE DALAM UPAYA MENINGKATKAN OCCUPANCY RATE DAN JUMLAH PENGUNJUNG
}

\author{
Andrian Wijaya Putra ${ }^{1)}$, Suryono Herlambang ${ }^{2)}$ \\ 1)Program Studi S1 PWK, Fakultas Teknik, Universitas Tarumanagara, \\ andrian.345150011@stu.untar.ac.id \\ 2)Program Studi S1 PWK, Fakultas Teknik, Universitas Tarumanagara, suryonoh@ft.untar.ac.id
}

\begin{abstract}
Abstrak
Perkembangan property di Jakarta semakin meningkat setiap tahunnya, salah satunya adalah Mall atau pusat perbelanjaan yang berdiri di banyak lokasi di Jakarta dan merupakan destinasi paling umum untuk dijadikan tempat rekreasi untuk keluarga. Adanya pusat perbelanjaan atau mall tersebut diharapkan dapat membantu meningkatkan siklus perekonomian dan membantu menambah jumlah lapangan pekerjaan di Jakarta. Tingginya tingkat pertumbuhan Pusat perbelanjaan di ibukota menyebabkan ada banyak pusat perbelanjaan yang tidak mampu bersaing dengan pusat perbelanjaan lainnya. Hal ini yang membuat pusat-pusat perbelanjaan di Jakarta menjadi sepi pengunjung dan mengalami penurunan occupancy rate. Mahaka Square merupakan salah satu pusat perbelanjaan yang mengalami hal tersebut yang berlokasi di Kelapa Gading dengan area seluas 2,6 ha dengan Arena olahraga berstandar internasional dan hotel, sehingga perlu dilakukan regenerasi pusat perbelanjaan dengan cara mengikuti trend aktivitas olahraga dan gaya hidup sehat anak usia muda produktif agar dapat bersaing dengan kompetitor. Melalui penelitian ini dilakukan studi mengenai Strategi pengelolaan Mahaka Square untuk mengetahui kondisi fisik bangunan eksisting Mahaka Square serta potensi Mahaka square dalam bersaing di pasar agar dapat meningkatkan occupancy rate dan jumlah pengunjung. Analisis yang dilakukan adalah analisis lokasi, analisis bangunan, analisis pasar, analisis preferensi pengunjung, dan analisis tenant mix. Alat yang digunakan dalam penelitian ini adalah diagram kartesius dan deskriptif kualitatif. Hasil dari penelitian ini adalah mengetahui apakah mahaka square perlu dilakukan perubahan fisik dari segi bangunan serta tenant -tenant yang seharusnya dimasukkan ke dalam Mahaka Square agar dapat meningkatkan occupancy rate dan jumlah pengunjung.
\end{abstract}

Kata Kunci: regenerasi pusat perbelanjaan; arena olahraga; aktivitas olahraga; gaya hidup sehat

\begin{abstract}
Property developments in Jakarta are increasing every year, one of which is a mall or shopping center located in many locations in Jakarta and is the most common destination for family recreation. The existence of a shopping center or mall is expected to help increase the economic cycle and help increase the number of jobs in Jakarta. The high level of growth Shopping centers in Jakarta cause there are many shopping centers that are not able to compete with other shopping centers. This is what makes shopping centers in Jakarta become quiet and experience a decline in occupancy rates. Mahaka Square is one of the shopping centers that experienced this, located in Kelapa Gading with an area of 2.6 ha with international standard sports arenas and hotels, so that shopping centers need to be regenerated by following the trend of sports and healthy lifestyles in young generation in order to compete with competitors. Through this study a study was conducted on the management strategy of Mahaka Square to determine the physical condition of existing Mahaka Square buildings and the potential of Mahaka Square in competing in the market in order to increase occupancy rates and number of visitors. The analysis carried out was location analysis, building analysis, market analysis, visitor preference analysis, and tenant mix analysis. The tools used in this study are cartesian diagrams and qualitative descriptive. The results of this study are to find out whether mahaka square needs to be physically changed in terms of buildings and tenants that should be included in Mahaka Square in order to increase occupancy rates and number of visitors.
\end{abstract}

Keywords: shopping center regeneration; sports arena; sports activities; healthy lifestyle 


\section{PENDAHULUAN}

Perkembangan property di Jakarta semakin meningkat setiap tahunnya, salah satunya adalah Mall/pusat perbelanjaan yang berdiri di banyak lokasi di Jakarta dan merupakan destinasi paling umum untuk dijadikan tempat rekreasi untuk keluarga. Adanya pusat perbelanjaan atau mall tersebut diharapkan dapat membantu meningkatkan siklus perekonomian dan membantu menambah jumlah lapangan pekerjaan di Jakarta.

Kelapa Gading sendiri merupakan daerah dengan pengembangan mall yang cukup banyak seperti Mall Artha Gading, Mall Kelapa Gading, Mall of Indonesia, Mahaka Square, Bella Terra Lifestyle, dll. Dengan banyaknya jumlah mall di daerah tersebut tentunya Mall/Pusat perbelanjaan memiliki keunikan masing-masing yang diharapkan dapat bersaing dengan mallmall atau pusat perbelanjaan lain dengan adanya persaingan yang tinggi tersebut membuat setiap mall berlomba-lomba menghadirkan konsep yang lebih menarik dan kreatif walaupun demikian tidak jarang ada pusat perbelanjaan yang tidak laku yang menyebabkan mall/ pusat perbelanjaan menjadi sepi pengunjung dan penyewa seperti Mahaka Square.

Mahaka Square merupakan salah satu mall di Indonesia dengan Indoor Arena yang bertaraf internasional dan modern serta merupakan satu-satunya mall dengan konsep Sports, Educations, Hobbies dan Entertainment. Terletak di tengah - tengah kawasan terpadu Kelapa Gading yaitu kawasan perumahan, perdagangan, perkantoran dan sekolah. Mahaka Square dengan luas $26.000 \mathrm{~m}^{2}$ memiliki fasilitas komersial yang terintegrasi dan saling bersinergi yaitu Arena Indoor Britama yang bertaraf Internasional dan Hotel Santika.

Namun 3 fasilitas komersial yang bersinergi di Mahaka Square ternyata belum cukup baik dan memiliki beberapa permasalahan yakni rendahnya occupancy rate dan jumlah pengunjung sehingga diperlukan strategi pengelolaan yang lebih baik dalam upaya meningkatkan occupancy rate dan jumlah pengunjung di Mahaka square. Mahaka Square jika dikelola dengan baik akan menarik minat pengunjung dari masyarakat sekitar Kelapa Gading maupun diluar. Serta memberikan edukasi kepada para pengunjung untuk tau dimana pusat perbelanjaan dengan tema One Stop Sport and Healthy Lifestyle. Adapun tujuan dari penelitian ini sebagai berikut:

a. Mengidentifikasi penyebab tingkat occupancy rate yang rendah di dalam Mahaka Square

b. Mengidentifikasi penyebab tingkat arus pengunjung yang rendah di dalam Mahaka Square.

c. Memberikan rekomendasi pengelolaan yang baik terhadap Mahaka Square.

\section{KAJIAN LITERATUR}

Menurut International Council of Shopping Centre (ICSC), definisi pusat perbelanjaan adalah sekelompok lokasi usaha ritel dan usaha komersial lainnya yang direncanakan, dikembangkan, dimiliki, dan dikelola suatu property tunggal.

Menurut Lynda dan Tong (2005), fasilitas penunjang kenyamanan atau kemudahan pengunjung adalah fasilitas yang ditawarkan oleh pusat perbelanjaan untuk mendukung suasana berbelanja yang nyaman dan mudah bagi pengunjung. Beberapa fasilitas tersebut yakni:

a. Kapasitas Parkir adalah kemampuan suatu lokasi pusat perbelanjaan untuk menampung kendaraan penyewa ataupun pengunjung dari pusat perbelanjaan.

b. Pendingin Ruangan adalah syarat mutlak bagi pengelola pusat perbelanjaan karena berhubungan dengan kenyamanan pengunjung ataupun penyewa dalam melakukan kegiatan bisnis.

c. Listrik dan Generator fasilitas utama yang harus dimiliki, tingkat kestabilan tegangan dan kemampuan supply listrik menjadi nilai lebih bagi penyewa karena akan memberikan rasa aman dari bahaya kebakaran yang diakibatkan oleh korsleting listrik.

d. Lift dan Eskalator lebih efisien dibandingkan lift untuk memudahkan pengerakan pengunjung dalam jumlah besar secara teratur. Dari escalator, pengunjung dapat lebih banyak melihat toko-toko di pusat perbelanjaan dibandingkan dengan mereka yang menggunakan lift. 
e. Penempatan Toilet sehrusnya disesuaikan dengan tema pusat perbelanjaan, sasaran pengunjung dan kemudahan pemeliharaan.

f. Telepon Umum sebagai sarana telekomunikasi yang bersifat umum dan digunakan untuk kepentingan bersama.

g. Bank atau ATM digunakan sebagai tempat atau sarana dari perputaran uang yang ada, dan juga keberadaan bank sangat memudahkan bagi pengunjung yang akan bertransaksi. Dikarenakan factor keamanan yang semakin tidak menentu dan tentunya alternatif lain adalah dengan menggunakan ATM sebagai alat untuk bertransaksi.

\section{METODE}

Penelitian ini terdapat dua jenis data yakni data primer dan data sekunder, antara lain sebagai berikut :

a. Data Primer merupakan data yang didapat langsung dari objek penelitian. Teknik pengumpulan data primer yaitu dengan Survei Lapangan, wawancaradan Kuesioner.

b. Data Sekunder merupakan data yang didapatkan dari berbagai sumber yang relevan seperti buku, jurnal, dokumen-dokumen pemerintah serta sumber dari internet yang dapat dipertanggung jawabkan. Data sekunder yang diperoleh adalah Peraturan yang terkait dengan Pengelolaan Mahaka Square, Dokumentasi dan data pendukung Mahaka Square, dan Data makro Kecamatan Kelapa Gading

c. Metode Pengolahan Data \& Alat Pengolahan (Analisis) adalah Analisis Lokasi (Deskriptif), Analisis Bangunan (Deskriptif \& Benchmarking), Analisis Pasar (Deskriptif \& Benchmarking), Analisis Persepsi dan Preferensi (IPA, Deskriptif), dan Analisis Tenant Mix (Deskriptif)

\section{DISKUSI DAN HASIL}

\section{Profil Mahaka Square}

Mahaka Square terletak di Kecamatan Kelapa Gading yang berlokasi Jalan Kelapa Nias Raya. Mahaka Square memiliki luas lahan sebesar $26.000 \mathrm{~m} 2$ dan Luas bangunan $30.833 \mathrm{~m} 2$ dengan ketinggian bangunan 4 lantai. Mahaka Square sudah beroperasi sejak tahun 2003, sebelum menjadi mall peruntukkan sebelumnya adalah untuk Fasilitas umum dan sosial tetapi kemudian diizinkan menjadi Sport mall pada tahun 1991. Mahaka Square dikelola oleh PT Gamma Investa Lestari yang bergerak dibidang property management. Pada saat awal beroperasi yakni pada tahun 2013 Mahaka Square memilki kondisi yang sepi sehingga pihak Mahaka Square menyewakan hampir sebagian dari total 250 unit kios kepada Hotel santika yakni 122 unit.

Namun setelah disewakan kepada Hotel Santika ternyata tidak membantu meningkatkan penyewa jumlah kios sehingga tersisa masih banyak yang kosong dan tidak tersewa. Meskipun menurut data pengelola jumlah tenant terus mengalami kenaikan dari tahun 2016 - 2018. Hasil Survey yang didapatkan mengenai jumlah tenant mix eksiting pada tahun 2018 yakni sebanyak 39 tenant dengan jumlah occupany rate yang rendah yakni $44.5 \%$ dari 128 kios yang tersedia untuk disewakan. Padahal Harga sewa Mahaka Square tergolong murah untuk Harga sewa di Kelapa Gading. Meskipun memiliki Fasiltias kebersihan dan keamanan yang cukup lengkap nyatanya Mahaka Square masih sepi pegunjung dan penyewa.

\section{Analisis Lokasi}

Aksesibilitas

Mahaka Square memiliki lokasi yang strategis karena berada di di Jalan Raya Kelapa Nias Blok HF 3 yang merupakan jalan Kolektor. Kelapa gading memiliki 2 pintu masuk yakni pintu masuk melewati Jl. Perintis kemerdekaan dan pintu masuk dari Jalan Raya Yos Sudarso. Mahaka Square terletak dekat dengan pintu masuk dan keluar Kelapa Gading Jl. Yos Sudarso. Mahaka Square juga dekat dengan exit Tol Tanjung priok dan masuk Tol Jakarta Inner Ring Road yakni berjarak kurang lebih 2 dan $3 \mathrm{~km}$. 


\section{Jaringan Transportasi Umum}

Jaringan transportasi Mahaka Square, dapat dilihat bahwa Mahaka Square memiliki jaringan transportasi umum yang baik karena banyak transportasi umum yang memiliki rute transportasi melewati Jalan Raya Kelapa Nias sehingga hal tersebut dapat memudahkan untuk mencapainya. Tabel berikut merupakan transportasi umum berupa angkutan umum yang memiliki rute transportasi melewati Jalan Raya Kelapa Nias, Kelapa Gading

Tabel 1 : Jaringan Angkutan Umum

\begin{tabular}{lll}
\hline No. & Nama Angkutan Umum & \\
\hline 1. & Kopaja 27 & $\begin{array}{l}\text { Pasar Senen - Jalan Gunung Sahari - Mangga Dua - Ancol - Sunter } \\
\text { - Mal Sunter - Plumpang - Kelapa Gading }\end{array}$ \\
\hline 2. & Mikrolet 30 A & Tanjung Priok - Plumpang - Kelapa Gading - Pulogadung \\
\hline 3. & Mikrolet 37 & Pasar Senen - Sumur Batu - Kelapa Gading - Pulogadung \\
\hline 4. & KWK 04 & Kelapa Gading - Mal Artha Gading - Mal Kelapa Gading - \\
& Apartemen Gading Nias Residence - Pegangsaan Dua \\
\hline 5. & KWK 13 & Rawamangun - Pulomas - Jalan Perintis Kemerdekaan - Kelapa \\
& & Gading \\
\hline 6. & Busway & Sunter Kelapa Gading \& ASMI \\
\hline 7. & Metromini 07 & Pasar Senen - Jalan Suprapto - Cempaka Putih - Cempaka Mas - \\
& & Jalan Jenderal Ahmad Yani - Kelapa Gading - Plumpang - Koja - \\
& Semper
\end{tabular}

Sumber: Penulis, 2019

\section{Kondisi Lingkungan sekitar}

Kondisi lingkungan sekitar dapat dilihat bahwa penggunaan lahan disekitar Mahaka Square adalah Hunian, Komersial, Fasilitas pendidikan serta Hunian Campuran.

\section{Analisis Bangunan}

Analisis ini akan menggambarkan keseluruhan kondisi fisik dari bangunan Mahaka Square yang ditentukan beberapa indicator bangunan yakni, life cycle banguanan, eksterior bangunan, interior bangunan, pencahayaan interior dan eksterior, kebutuhan parkir serta fasilitas bangunan.

Tabel 2: Perbandingan Mall Renovasi

\begin{tabular}{cccc}
\hline Komponen & Mahaka Square & Taman Anggrek & Mall Of Indonesia \\
\hline Lokasi & Jalan Raya Kelapa Nias & Jalan Letjen Sparman & $\begin{array}{c}\text { Jalan Boulevard Barat } \\
\text { Raya }\end{array}$ \\
\hline Luas & $26.000 \mathrm{~m} 2$ & $360.000 \mathrm{~m} 2$ & $100.000 \mathrm{~m} 2$ \\
\hline Occupancy Rate(\%) & $44,5 \%$ & $75 \%$ & $70 \%$ \\
\hline Tahun Operasi & 2003 & 1996 & 2008 \\
\hline Renovasi & 2013 & 2012 dan 2015 & $\mathrm{v}$ \\
\hline Parkir Basement & $\mathrm{x}$ & $\mathrm{v}$ & $\mathrm{v}$ \\
\hline Parkir Gedung & $\mathrm{x}$ & $\mathrm{v}$ & $\mathrm{v}$ \\
\hline Parkir Outdoor & $\mathrm{v}$ & 12.000 & 14.000 \\
\hline Kapasitas Parkir & 400 & Komunitas Ice Skating, & Food Festival, E-sports, \\
\hline Event & E-sports, & Acara Musik, dll & komunitas Unicorn Land \\
\hline
\end{tabular}

Sumber: Penulis, 2019

\section{Stage of Life Cycle}

Dari segi Stage of Life Cycle dapat dilihat usaha yang dilakukan oleh Mahaka Square tidak sebaik yang dilakukan oleh kompetitornya yakni Mall of Indonesia dan Taman Anggrek, dimana pada fase mature-decline Mall kompetitor melakukan promosi dengan menarik tenant baru serta melakukan kegiatan event dan social media serta melakukan renovasi sedangkan Mahaka 
Square tidak melakukan kegiatan tersebut sehingga Mahaka Square Harus melakukan renovasi besar untuk mall dan meningkatkan pemasan Mahaka Square agar dapat meningkatkan Occupancy rate dan Jumlah Pengunjung

\section{Fasad}

Façade yang dimiliki oleh Mahaka Square saat ini, sudah terlihat tua karena memiliki warna gedung yang tidak mencolok serta desain yang terkesan tidak modern (kuno), diikuti dengan penempatan tulisan Mahaka Square yang berada dibawah sehingga dari kejauhan yang terlihat adalah Hotel Santika bukan Mahaka Square.

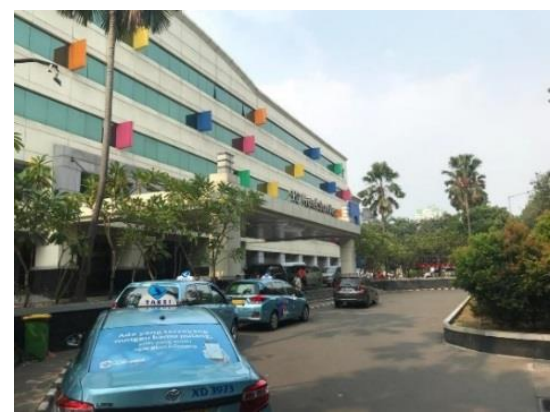

Gambar 1. Tampak depan Mahaka Square Sumber: Penulis, 2019

Hal ini yang membuat citra Mahaka Square menjadi hotel, sehingga kita harus melakukan beberapa perubahan terhadap Façade yang dimiliki oleh Mahaka Square seperti mengubah bagian depan Mahaka Square mulai dari penempatan tulisan yang lebih jelas dan mengganti warna cat agar lebih mencolok dan dapat mencuri pandangan saat kita melewati bangunan ini.

\section{Pintu Masuk}

Mahaka Square memiliki 3 pintu masuk yakni Pintu Utara, Timur dan selatan, tetapi tidak memiliki Lobby khusus untuk penumpang turun karena bagian depan tempat drop-off langsung disewakan kepada Hotel Santika dan mereka tidak membuka akses dari hotel ke Mahaka Square sehingga jika di drop di tempat drop-off langsung kita harus berjalan sekitar 50 meter menuju pintu masuk Mahaka Square atau alternative lainnya pada saat ingin menurunkan penumpang harus masuk ke dalam mall terlebih dahulu untuk melakukan drop- off dan membayar parkir. Mahaka Square juga tidak dilengkapi dengan pusat informasi untuk pengunjung.

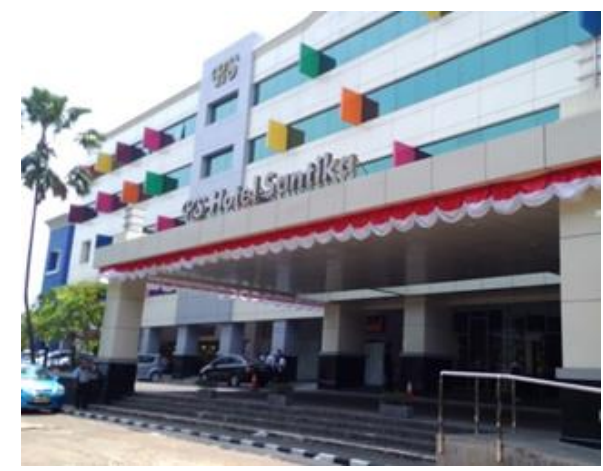

Gambar 2. Drop-off Mahaka Square Sumber: Penulis, 2019

Sehingga harus dilakukan beberapa perubahan yakni menyediakan pusat informasi untuk Mahaka Square dan membebaskan tarif untuk drop off maximal 15 menit free untuk drop-off atau membuka akses dari hotel santika menuju Mahaka Square agar dapat memberikan 
kenyamaan bagi pengunjung serta memudahkan pengunjung yang baru pertama kali berkunjung dan tidak adanya beban dalam membayar parkir pada saat drop-off.

\section{Pencahayaan Malam Hari}

Mahaka Square jika dibandingkan pencahayaanya dengan Mall lain yang berada dalam area tersebut dapat dilihat perbedaan yang cukup signifikan pada malam hari, berikut adalah foto beberapa pencahayaan Mall lain di area tersebut.

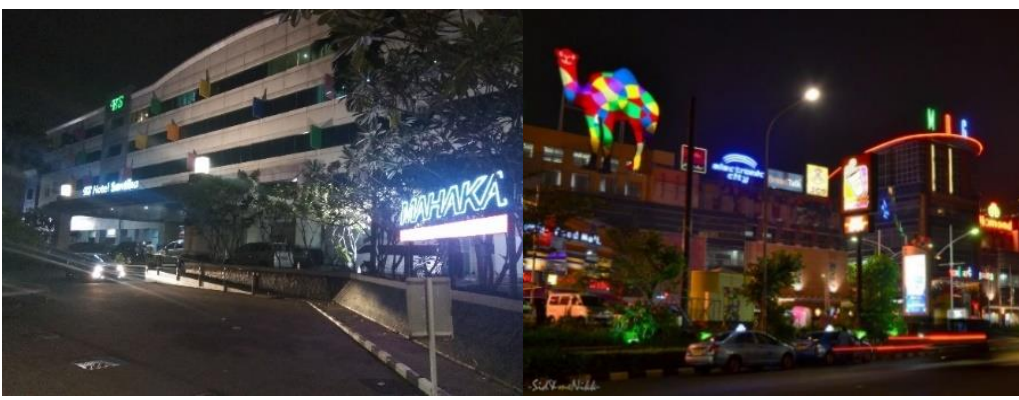

Gambar 3. Night Lighting vs Competitor

Sumber: Penulis, 2019

Tabel 3 : Hasil Pengamatan Kondisi Fisik Bangunan Mahaka Square

\begin{tabular}{|c|c|c|c|}
\hline $\begin{array}{l}\text { Komponen } \\
\text { Fisik } \\
\text { Bangunan }\end{array}$ & Variabel & Kesimpulan (hasil Observasi) & Keterangan \\
\hline $\begin{array}{l}\text { Fisik } \\
\text { Bangunan }\end{array}$ & & $\begin{array}{l}\text { Dari stage of life cycle dapat disimpulkan bahwa } \\
\text { bangunan Mahaka Square perlu dilakukan renovasi } \\
\text { mayor untuk menarik minat pengunjung, karena Fisik } \\
\text { bangunan yang sudah tua }\end{array}$ & $\begin{array}{ll}\text { Perlu dilakukan } \\
\text { renovasi }\end{array}$ \\
\hline \multirow[t]{3}{*}{$\begin{array}{l}\text { Eksterior } \\
\text { Bangunan }\end{array}$} & Façade & $\begin{array}{l}\text { Façade Mahaka Square ada baiknya diubah agar menjadi } \\
\text { lebih menarik bisa dimulai dari pembaharuan cat gedung } \\
\text { agar fasad bisa kelihatan lebih modern. }\end{array}$ & Perlu ditingkatkan \\
\hline & $\begin{array}{l}\text { Building } \\
\text { Entrance }\end{array}$ & $\begin{array}{l}\text { Perlu menyediakan pusat informasi untuk Mahaka } \\
\text { Square dan membebaskan tarif untuk drop off maximal } \\
15 \text { menit free untuk drop-off atau membuka akses dari } \\
\text { hotel santika menuju Mahaka Square }\end{array}$ & Perlu ditingkatkan \\
\hline & $\begin{array}{l}\text { Night } \\
\text { Lighting }\end{array}$ & $\begin{array}{l}\text { Pencahayaan pada malam hari yang masih kurang pada } \\
\text { Mahaka Square, sehingga Mahaka square tidak begitu } \\
\text { mudah menarik perhatian karena menggunakan } \\
\text { penerangan yang biasa saja serta penerangan lokasi } \\
\text { parkir yang cukup gelap. Jika dibandingkan dengan } \\
\text { competitor disekitarnya maka penerangan harus } \\
\text { diperbaharui }\end{array}$ & $\begin{array}{l}\text { Perlu Ditingkatkan } \\
\text { Dengan cara } \\
\text { menggunakan } \\
\text { variansi } \\
\text { penerangan seperti } \\
\text { pada mall } \\
\text { kompetitor }\end{array}$ \\
\hline \multirow[t]{2}{*}{$\begin{array}{l}\text { Interior } \\
\text { Bangunan }\end{array}$} & $\begin{array}{l}\text { SIrkulasi } \\
\text { Horizontal }\end{array}$ & $\begin{array}{l}\text { mempunyai sirkulasi horizontal yang baik karena } \\
\text { bentuknya yang mengeliling, dengan memiliki koridor } \\
\text { dan selasar yang menghubungkan tenant satu dengan } \\
\text { tenant lainnya, }\end{array}$ & Dipertahankan \\
\hline & $\begin{array}{l}\text { Sirkulasi } \\
\text { Vertikal }\end{array}$ & $\begin{array}{l}\text { Meskipun jumlah escalator di Mahaka Square cukup } \\
\text { banyak tetapi tidak jarang escalator tidak dinyalakan } \\
\text { karena sepinya pengunjung. }\end{array}$ & Perlu Ditingkatkan \\
\hline Fasilitas & & $\begin{array}{l}\text { Fasilitas umum pada Mahaka Square cukup terawatt } \\
\text { meskipun material yang digunakan sudah tua tetapi } \\
\text { dirawat dengan baik }\end{array}$ & $\begin{array}{l}\text { Perlu } \\
\text { dipertahankan }\end{array}$ \\
\hline Parkir & & $\begin{array}{l}\text { Parkir Mahaka square terdiri dari } 400 \text { parkir mobil dan } \\
\text { motor sedangkan dari satuan kebutuhan parkir } \\
\text { memerlukan } 1040 \text { unit sehingga perlu ditingkatkan } \\
\text { dengan cara menambah lahan parkir. }\end{array}$ & Perlu ditingkatkan \\
\hline
\end{tabular}

Sumber: Penulis, 2019 


\section{Analisis Pasar}

Dalam hal pembangunan seperti pembangunan pusat perbelanjaan, perlu dilakukannya prediksi terhadap potensi pasar. Pembangunan pusat perbelanjaan di Jakarta Utara seperti Kelapa Gading perlu diimbangi dengan demand yang memadai, karena apabila tidak diimbangi dengan demandnya maka akan mengakibatkan banyaknya properti komersial (mal) yang terlihat sepi penyewa (tenant), maka dari itu diperlukannya suatu analisa pasar. Analisa pasar yang akan dilakukan mencakup kondisi ekonomi makro serta kondisi supply dan demand untuk retail di Kelapa Gading.

Supply and Demand Pusat Perbelanjaan

Tabel 4: Data Supply dan Demand Pusat Perbelanjaan Kelapa Gading

\begin{tabular}{ccc}
\hline Tahun & Supply & Demand \\
\hline 2014 & 336,976 & 201,257 \\
\hline 2015 & 336,976 & 277,660 \\
\hline 2016 & 336,976 & 288,095 \\
\hline 2017 & 359,476 & 293,045 \\
\hline 2018 & 359,476 & 293,045 \\
\hline
\end{tabular}

Sumber : Penulis, 2019

Berdasarkan data diatas bahwa Supply pusat perbelanjaan di Kelapa Gading lebih besar dibandingkan dengan demand yakni pada tahun 2014 sampai 2016 supply sebesar $336.976 \mathrm{~m}^{2}$ dan demand yang terus mengalami kenaikan kemudian Kenaikan supply terjadi pada tahun 2017 dimana terdapat pusat perbelanjaan baru yakni Mall Bella Terra Lifestyle. Sebelumnya pada tahun 2014 sampai 2016 mall yang berada di Kelapa Gading ada 6 yakni: Mahaka Square, Mall Artha Gading, Mall Of Indonesia, Mall Kelapa Gading, dan Bella Terra Lifestyle yang terbaru pada tahun 2017

\section{Kelompok Usia Produktif}

Kependudukan di Kecamatan Kelapa Gading didominasi oleh penduduk dengan kelompok usia produktif yakni 15-64 tahun dengan jumlah penduduk sebesar 93.777 jiwa dari total kependudukan kelapa gading 137.538 jiwa . Kelompok usia produktif yang terbanyak berada pada kelompok usia 15-29 yakni didominasi oleh remaja dan dewasa muda. Hal ini menyebabkan adanya potensi kelompok usia tersebut untuk melakukan aktivitas-aktivitas olahraga yang dapat ditampung/diserap oleh Mahaka Square sebagai Sport Mall di Kelapa gading

Tabel 5: Kelompok Usia Produktif Kelapa Gading

\begin{tabular}{ccccc}
\hline \multirow{2}{*}{ No } & Umur & \multicolumn{3}{c}{ Kelurahan } \\
\cline { 2 - 5 } & & $\begin{array}{c}\text { Kelapa Gading } \\
\text { Barat }\end{array}$ & $\begin{array}{c}\text { Kelapa Gading } \\
\text { Timur }\end{array}$ & Pegangsaan Dua \\
\hline $\mathbf{1}$ & $0-4$ & 2.955 & 2.660 & 4.013 \\
\hline $\mathbf{2}$ & $5-9$ & 3.386 & 2.653 & 4.281 \\
\hline $\mathbf{3}$ & $10-14$ & 3.213 & 2.457 & 4.036 \\
\hline $\mathbf{4}$ & $15-19$ & 3.955 & 4.161 & 3.411 \\
\hline $\mathbf{5}$ & $20-24$ & 5.668 & 4.336 & 3.995 \\
\hline $\mathbf{6}$ & $25-29$ & 5.887 & 4.021 & 3.430 \\
\hline $\mathbf{7}$ & $30-34$ & 2.530 & 1.787 & 4.198 \\
\hline $\mathbf{8}$ & $35-39$ & 2.751 & 3.553 & 3.941 \\
\hline $\mathbf{9}$ & $40-44$ & 3.580 & 2.827 & 4.170 \\
\hline $\mathbf{1 0}$ & $45-49$ & 3.111 & 3.391 & 2.853 \\
\hline $\mathbf{1 1}$ & $50-54$ & 2.267 & 2.223 & 3.647 \\
\hline
\end{tabular}




\begin{tabular}{lcccc}
\hline 12 & $55-59$ & 1.754 & 2.395 & 2.856 \\
\hline 13 & $60-64$ & 1.385 & 2.293 & 2.069 \\
\hline 14 & $65-69$ & 1.033 & 1.650 & 1.297 \\
\hline 15 & $70-74$ & 829 & 798 & 668 \\
\hline 16 & $>75$ & 515 & 684 & 625 \\
\hline & Total & 42.827 & 40.889 & 53.822 \\
\hline
\end{tabular}

Sumber : Penulis, 2019

Fasilitas Pendidikan

Tabel 6: Fasilitas Pendidikan Kelapa Gading

\begin{tabular}{ccc}
\hline No & Pendidikan & Jarak \\
\hline 1 & Kwik Kian Gie School Of Business & $1,77 \mathrm{~km}$ \\
\hline 2 & STT Lintas Budaya & $1,19 \mathrm{~km}$ \\
\hline 3 & Institut Kesehatan Indonesia & $1,36 \mathrm{~km}$ \\
\hline 4 & NJIS Kelapa Gading & $1,21 \mathrm{~km}$ \\
\hline 5 & UKRIDA & $1,36 \mathrm{~km}$ \\
\hline 6 & Mahatma Gading International School & $1,60 \mathrm{~km}$ \\
\hline 7 & Penabur International School & $2,14 \mathrm{~km}$ \\
\hline 8 & SMA Mahatma Gading & $2,39 \mathrm{~km}$ \\
\hline 9 & SMP tunas Karya & $1,01 \mathrm{~km}$ \\
\hline 10 & Raffles Kampus & $1,22 \mathrm{~km}$ \\
\hline 11 & SMA Alazhar & $1,22 \mathrm{~km}$ \\
\hline 12 & Universitas Azzahra Kampus Kelapa Gading & $1,22 \mathrm{~km}$ \\
\hline 13 & SMAK PENABUR & $600 \mathrm{~m}$ \\
\hline 14 & SIS Kelapa Gading & $1,5 \mathrm{~km}$ \\
\hline
\end{tabular}

Sumber: Penulis, 2019

Dari table diatas dapat dilihat total keseluruhan Fasilitas Pendidikan yang berada di kelapa gading adalah 14 dengan jumlah murid 9.647 murid (menurut data kecamatan Kelapa Gading). Dari beberapa universitas dan sekolah diatas terdapat beberapa sekolah dan universitas yang tidak memiliki space untuk melakukan aktivitas olahraga dll karena bergabung dengan office tower dan mall seperti contoh Kwik Kian Gie, STT lintas Budaya, Institut Kesehatan Indonesia, serta Universitas Azzahra yang mengakibatkan adanya potensi untuk Mahaka Square menjadi tempat untuk sekolah dan universitas tersebut untuk dijadikan tempat olahraga/aktivitas.

\section{STP (Segmentation, Targeting and Positioning)}

Dalam segmentasi pasar ini terbagi menjadi geographic, demographic, psychographic, perilaku. Segmentasi pasar secara keseluruhan pada Mahaka Square yang didapatkan berdasarkan tempat asal pengunjung ialah merupakan masyarakat Kelapa Gading dengan persentase $92 \%$. Berdasarkan hasil kuesioner, diketahui bahwa rata-rata pengunjung Mahaka Square berupa mahasiswa dan pegawai swasta yang memiliki penghasilan $\mathrm{Rp} 4.000 .000-\mathrm{Rp}$ 7.000.000 dengan nilai persentase sebesar 50\%. Dan dapat diketahui pula rata-rata usia pengunjung Mahaka Square yaitu antara usia 18 - 25 dan 26 - 40 tahun karena memiliki presentase yang tidak jauh berbeda yakni $43 \%$ dan $50 \%$. Konsep Mahaka Square yang mengusung sport mall memiliki target pasar yang jelas yakni anak-anak usia produktif dan para pekerja kantoran berdasarkan segmentasi pasar pengunjung di dalam Mahaka Square dan Data 
kependudukan menurut usia Produktif di Kelapa Gading. Positioning Harga sewa Mahaka Square adalah yang terendah di Kecamatan Kelapa Gading dengan Harga sewa Rp. 285.000

\section{Komparasi Tenant}

Di dalam Komparasi Tenant akan dilakukan perbandingan dengan mall - mall yang memiliki konsep Healthy Food dan tenant sport yang baik. Komparasi Tenant tersebut berfungsi sebagai dasar luasan untuk tenant yang akan dimasukkan ke dalam Mahaka Square. Mall-mall tersebut adalah Grand Indonesia, Mall Kelapa Gading, Senayan City dan Central Park yang terkenal dengan Healthy Food dan tenant sport yang baik dan lengkap.

Tabel 7: Komparasi Tenant Sport \& Healthy F\&B Mall

\begin{tabular}{|c|c|c|c|c|c|c|}
\hline \multirow{2}{*}{$\begin{array}{c}\text { Kategori } \\
\text { Sport }\end{array}$} & \multicolumn{2}{|c|}{ Grand Indonesia } & \multicolumn{2}{|c|}{ Senayan City } & \multicolumn{2}{|c|}{ Central Park } \\
\hline & Tenant & Luas & Tenant & Luas & Tenant & Luas \\
\hline \multirow[t]{2}{*}{ Indoor } & $\begin{array}{c}\text { Under } \\
\text { Armour }\end{array}$ & 301 & $\begin{array}{l}\text { Under } \\
\text { Armour }\end{array}$ & 270 & $\begin{array}{c}\text { Under } \\
\text { Armour }\end{array}$ & 301 \\
\hline & & & Kettler & 360 & & \\
\hline Outdoor & $\begin{array}{c}\text { The north } \\
\text { Face }\end{array}$ & 150 & North Face & 138 & & \\
\hline \multirow[t]{5}{*}{$\begin{array}{c}\text { Olahraga } \\
\text { Bola Besar } \\
\text { dan kecil }\end{array}$} & $\begin{array}{l}\text { Planet } \\
\text { Sports }\end{array}$ & 929 & $\begin{array}{c}\text { Planet } \\
\text { Sports.net }\end{array}$ & 1181 & $\begin{array}{c}\text { Planet } \\
\text { Sport \& } \\
\text { Puma }\end{array}$ & 762 \\
\hline & The & & The & & & \\
\hline & $\begin{array}{l}\text { Athletes } \\
\text { Foot }\end{array}$ & 500 & $\begin{array}{l}\text { Athlete's } \\
\text { Foot }\end{array}$ & 93 & & \\
\hline & $\begin{array}{c}\text { Fisik } \\
\text { Football }\end{array}$ & 150 & $\begin{array}{c}\text { Fisik } \\
\text { Football } \\
\end{array}$ & 151 & & \\
\hline & Hoops & 200 & Wilio & 124 & & \\
\hline \multirow[t]{8}{*}{$\begin{array}{c}\text { Olahraga } \\
\text { Atletik }\end{array}$} & Adidas & 347 & Nike & 1997 & Adidas & 374 \\
\hline & Nike & 900 & Puma & 366 & Nike & 394 \\
\hline & $2 x u$ & 200 & Adidas & 448 & Puma & 85 \\
\hline & asics & 190 & & & & \\
\hline & Hurley & 150 & & & & \\
\hline & $\begin{array}{c}\text { New } \\
\text { Balance }\end{array}$ & 500 & & & & \\
\hline & Puma & 97 & & & & \\
\hline & Saucony & 60 & & & & \\
\hline \multirow{2}{*}{$F \& B$} & \multicolumn{2}{|c|}{ Grand Indonesia } & \multicolumn{2}{|c|}{ Senayan City } & \multicolumn{2}{|c|}{ Central Park } \\
\hline & Tenant & Luas & Tenant & Luas & Tenant & Luas \\
\hline \multirow{2}{*}{ Healthy F\&B } & Rejuve & 10 & SaladStop! & 94 & Rejuve & 8 \\
\hline & SaladStop! & 94 & & & Salad stop & 100 \\
\hline \multirow{2}{*}{ Sport F\&B } & & & & & Pizza Sport & \\
\hline & & & & & Bar Ebira & 150 \\
\hline
\end{tabular}

Sumber : Penulis, 2019

\section{Analisis Preferensi dan Persepsi Pengunjung}

Dalam Analisis Preferensi dan Persepsi Pengunjung ini kita akan membahas mengenai persepsi dan preferensi pengunjung mahaka square terhadap pengelolaan yang sudah ada, serta tenant yang sesuai dengan keinginan masyarakat. 
Indikator Pengelolaan

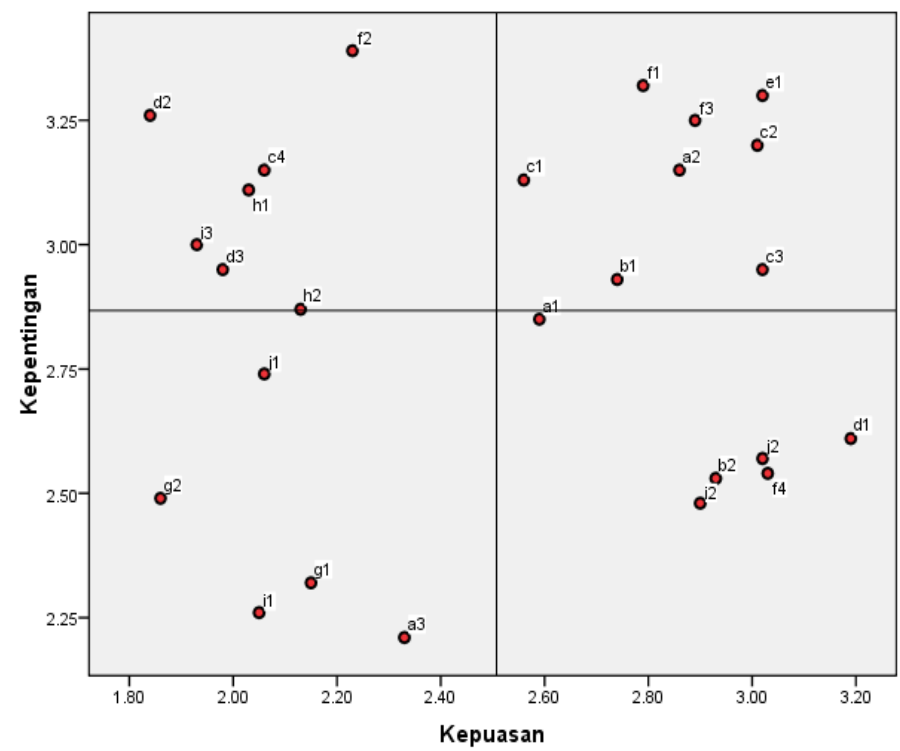

Gambar 4. Diagram Kartesius

Sumber : Penulis, 2019

- Kuadran A ( yang paling penting bagi pengunjung \& harus ditingkatkan)

Design Exterior, Design Interior, Kelengkapan Produk, Kualitas Produk, Pencahayaan Luar Mall, Toko yang menarik.

- Kuadran B ( yang penting \& harus dipertahankan)

Akses yang baik, sirkulasi horizontal dan vertical, udara, keamanan dan kebersihan, tempat sampah di setiap sudut.

- Kuadran C ( diabaikan)

Mudah terlihat dari kejauhan, petunjuk dalam \& luar mall, penempatan lokasi toko, parkir yang mudah.

- Kuadran D ( Tidak terlalu penting)

Lokasi strategis, Pintu masuk utama, toilet yang bersih, harga yang terjangkau, anchor tenant yang menarik, ketersediaan tempat parkir.

\section{Tenant}

Dapat diketahui dari hasil diagram di atas berdasarkan kuesioner yang telah dibagikan menunjukkan bahwa para pengunjung Mahaka Square mengharapkan adanya tenant F\&B dan Hobby dengan persentase $38 \%$ dan $33 \%$. Tenant-tenant $F \& B$ yang disukai pengunjung adalah Salad Stop, Burgreens Eatery, HONU Poke Bar, BerryWell, Rejuve, dan Naked Press karena tenant-tenant F\&B tersebut merupakan salah satu pioneer Trend Healthy F\&B di Indonesia. Sedangkan untuk Hobby yang paling diminati adalah Olahraga bola besar dan kecil.

\section{Analisis Tenant Mix}

Analisis Tenant mix berfungsi mengetahui komposisi tenant di Mahaka Square apakah sudah sesuai dengan keinginan pasar dan kemudian menentukan tenant yang sesuai untuk Mahaka Square. Berdasarkan hasil kuesioner, dapat diketahui bahwa pengunjung Mahaka Square lebih banyak menyukai jenis tenant F\&B dan Hobby dengan jumlah persentase sebesar 38\% dan 33\% oleh karena itu dari jumlah sampel kuesioner yang di ambil diketahui bahwa para pengunjung Mahaka Square lebih dominan atau lebih banyak yang mengharapkan jenis tenant tersebut, sedangkan jenis tenant tersebut hanya memiliki persentase sebesar $24 \%$ dan $5 \%$ sehingga 
terlihat adanya ketidaksesuaian antara supply dan demandnya. Yang mengakibatkan harus adanya penentuan tenant yang tepat sesuai dengan kebutuhan dan keinginan Pasar.

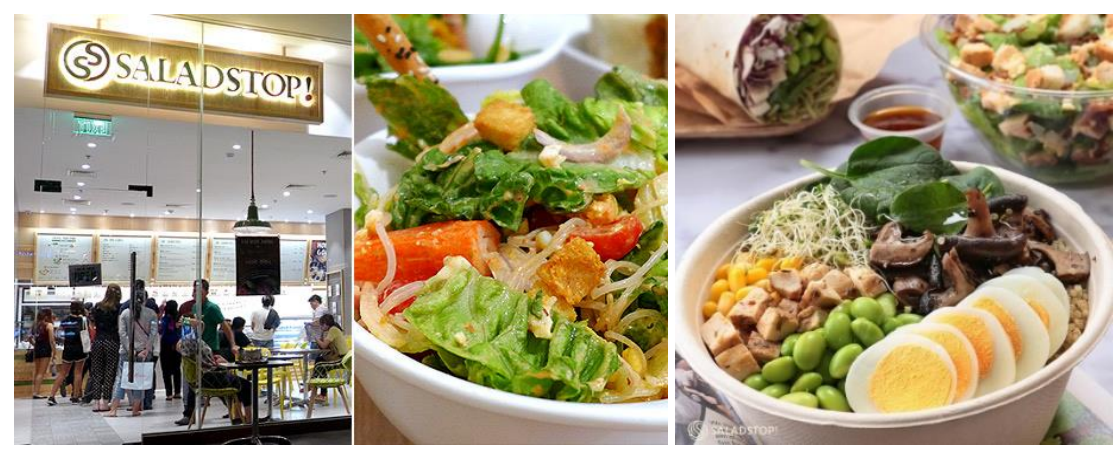

Gambar 5. Tenant Healthy F\&B

Sumber : Penulis, 2019

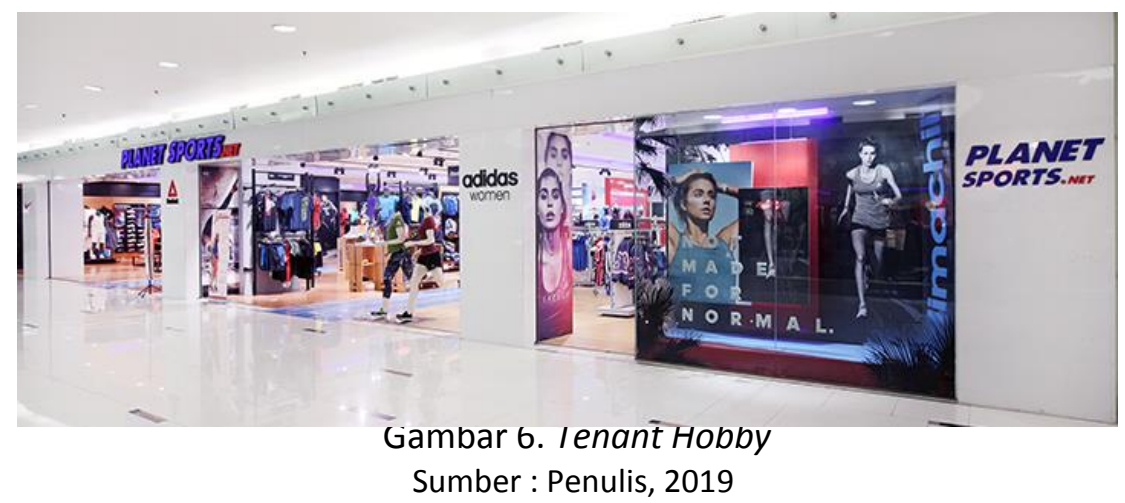

\section{Penentuan Tenant}

Dalam Penentuan Tenant sport ini dilakukan di lantai satu Mahaka Square karena memiliki tingkat vacancy rate tertinggi pada lantai ini juga didasarkan pada tenant - tenant Hobby umumnya tidak pernah berada di lantai dasar selalu 1 lantai di atas lantai dasar. Sedangkan untuk Tenant F\&B diletakkan di It dasar untuk menarik perhatian pengunjung.

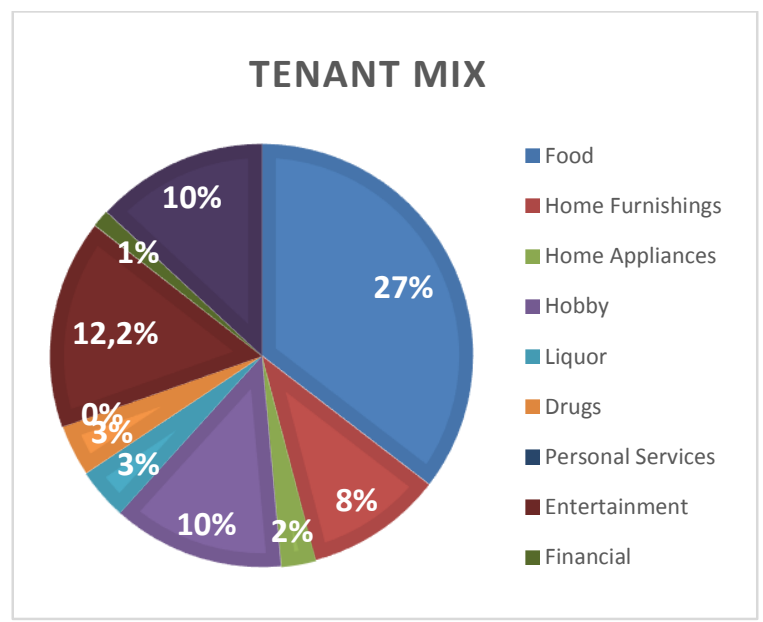

Gambar 7. Diagram Tenant Mix

Sumber : Penulis, 2019 


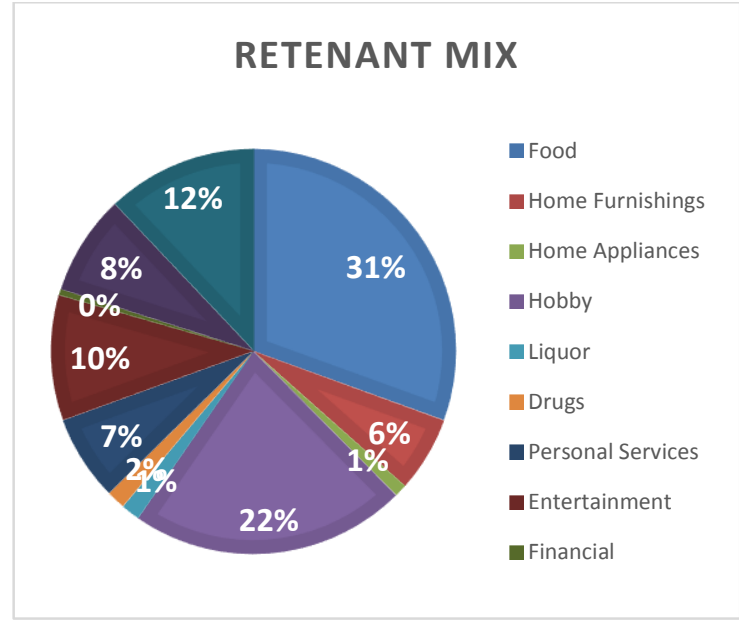

Gambar 8. Diagram Re-Tenant Mix

Sumber : Penulis, 2019

Setelah dilakukan penentuan tenant terhadap lantai dasar dan lantai 1 kemudian kita akan membandingkan persentase tenant mix sesudah dan sebelum melakukan retenant mix di Mahaka Square. Dapat dilihat terjadi perubahan persentase pada Tenant F\&B dan Hobby karena terjadi penambahan 5 Tenant F\&B dan 7 Tenant Hobby Sporting goods di Mahaka Square. Tenant F\&B dari $27 \%$ menjadi $30,5 \%$ sedangkan tenant Hobby terjadi kenaikan signifikan yakni dari $10 \%$ menjadi $22 \%$ karena memiliki luasan yang lebih besar.

\section{KESIMPULAN DAN SARAN}

\section{Kesimpulan}

1) Mahaka Square terletak di lokasi yang strategis karena dekat dengan pintu masuk dan keluar Kelapa gading serta dekat dengan Exit Tol Tanjung priok dan Entrance Tol Inner Ring Road. Mahaka Square juga dilewati oleh Transportasi Umum seperti Kopaja, Mikrolet dan Metromini serta kedepannya LRT akan beroperasi yang dapat menambah kemudahan akses menuju Mahaka Square. Mahaka Square berbatasan langung dengan komplek perumahan sehingga ada potensi hadirnya pengunjung

2) Kondisi fisik bangunan dalam pengelolaannya perlu dilakukan renovasi seperti bagian pada bagian eksterior terutama pada fasad bangunan yang sudah terlihat kuno serta membuka drop off langsung bagi pengunjung, serta pencahayaan pada malam hari yang masih kurang mencuri perhatian serta meningkatkan kebutuhan parkir Mahaka Square.

3) Occupancy rate diakibatkan kurangnya kegiatan promosi meskipun banyaknya kelompok usia produktif di kecamatan kelapa gading yang dapat diserap serta adanya Fasilitas Pendidikan dan komunitas yang tidak mempunyai tempat untuk melakukan Aktivitas Olahraga.

4) Menurut pengunjung diperlukan perbaikan design Ekterior dan Interior, tenant yang menarik, serta pemasaran melalui Social Media dan mengadakan Event Games, dan konser, serta menghadirkan tenant Healthy food dan Hobby di Mahaka Square agar dapat mendapatkan awareness.

5) Dengan menambahkan Tenant Healthy Food, Sport Bar dan Hobby diharapkan akan meningkatkan arus pengunjung karena berdasarkan analisis yang merekomendasikan tenant yang sedang trending disesuaikan dengan gaya hidup usia produktif pada saat ini. 


\section{Saran}

1) Pengelola seharusnya melakukan pemasaran yang lebih aktif tidak hanya melalui radio dan website karena teknik pemasaran tersebut sudah kuno dan pada zaman sekarang sudah jarang orang menggunakan 2 media tersebut

2) Pengelola seharusnya memanfaatkan konsep sport mall menjadi satu daya Tarik untuk pengunjung

3) Pemilik tenant harus ikut serta dalam meningkatkan arus jumlah pengunjung dengan cara bekerja sama dengan layanan Fintech yang memberikan diskon

\section{REFERENSI}

Baker. (1975). Definisi Pemasaran Menurut Para Ahli. Marketing (Pemasaran).

Bruwer, J. (1997). Solving the ideal tenant mix puzzle for a proposed shopping centre: a practical research methodology: Property Management, v. 15, p. 160-172.

Greenspan, J. (1987). Solving the tenant mix puzzle in your shopping center: Journal of Property Management, p. 27-31.

ICSC (1999). Shopping Center Management, International Council of Shopping Centers Publications Department, New York.

James F.J. (1982), Economic Impacts of Private Reinvestment in Older Regional ShC, Growth \& Change,Vol.16, No.3, pp.11-24;

Kirkup,M.H.,and Rafiq, M. (1994). Managing Tenant Mix in New Shopping Centres: International Journal of Retail \& Distribution Management, v. 22, p. 29-37.

Kotler. (2000). Definisi Pemasaran Menurut Para Ahli. Marketing (Pemasaran).

Lowry J.R. (1997). The Life Cycle of Shopping Centers, Business Horizons, January-February pp.77-86.

Wong K.C., Norman G. (1994). The Optimal Time of Renovating a Mall, The Journal of Real Estate Research,Winter, pp.33-47.

Zentes J., Swoboda B. (1998). Handelsmonitor I 98, Trends\&Visionen: Wo wird im Jahre 2005 Handelgemach, Deutscher Fachverlag, Frankfurt am Main. 